\title{
Ash reduction of corn stover by mild hydrothermal preprocessing
}

\author{
M. Toufiq Reza • Rachel Emerson • M. Helal Uddin • \\ Garold Gresham • Charles J. Coronella
}

Received: 8 February 2014 / Revised: 25 March 2014 / Accepted: 26 March 2014 / Published online: 22 April 2014

(C) The Author(s) 2014. This article is published with open access at Springerlink.com

\begin{abstract}
Lignocellulosic biomass such as corn stover can contain high ash content, which may act as an inhibitor in downstream conversion processes. Most of the structural ash in biomass is located in the cross-linked structure of lignin, which is mildly reactive in basic solutions. Four organic acids (formic, oxalic, tartaric, and citric) were evaluated for effectiveness in ash reduction, with limited success. Because of sodium citrate's chelating and basic characteristics, it is effective in ash removal. More than $75 \%$ of structural and $85 \%$ of whole ash was removed from the biomass by treatment with $0.1 \mathrm{~g}$ of sodium citrate per gram of biomass at $130{ }^{\circ} \mathrm{C}$ and 2.7 bar. FTIR, fiber analysis, and chemical analyses show that cellulose and hemicellulose were unaffected by the treatment. ICP-AES showed that all inorganics measured were reduced within the biomass feedstock, except sodium due to the addition of $\mathrm{Na}$ through the treatment. Sodium citrate addition to the preconversion process of corn stover is an effective way to reduced physiological ash content of the feedstock without negatively impacting carbohydrate and lignin content.
\end{abstract}

Keywords Demineralization · Chelation · Inorganic analysis $\cdot$ Lignocellulosic biomass $\cdot$ Biomass pretreatment

M. T. Reza $\cdot$ M. H. Uddin • C. J. Coronella $(\triangle)$

Department of Chemical \& Materials Engineering,

University of Nevada, Reno, MS0170, Reno, NV 89557, USA

e-mail: coronella@unr.edu

\section{T. Reza}

Leibniz Institute for Agricultural Engineering Potsdam-Bornim, Max-Eyth-Allee 100, 14469 Potsdam, Germany

R. Emerson • G. Gresham

Idaho National Laboratory, 1765 N. Yellowstone Hwy, Idaho Falls, ID 83415 , USA

\section{Introduction}

Lignocellulosic biomass (wood, grasses, and agricultural residues) are an alternative, renewable, and sustainable energy source with a large potential to address the increasing demands for alternative liquid fuels and green chemicals. These feedstocks do not directly compete with the food supply, but have a constrained usage due to their inherit characteristics and storage limitations [1]. About 450 million dry tons (Mt) of wood, energy crops, and agricultural residues, both primary and secondary, are available currently in the USA, and this amount is expected to increase to more than $1,000 \mathrm{Mt}$ by 2030 [2]. Feedstock supply and logistics of lignocellulosic biomass, such as wood, rice hulls, straw, and switchgrass, are challenging due to low bulk density, low energy density, and high ash content $[3,4]$. Chemically and physically consistent feedstocks can reduce or remove barriers that limit access to much of the potential US biomass resources, while helping to reduce biofuel production costs and enabling a national-scale biorefining industry [5].

In many thermochemical conversion processes (e.g., pyrolysis, fast pyrolysis, liquefaction) high mineral content has an adverse effect on the product output. The presence of alkali and earth alkali metals drastically decreases the production of levoglucosan in pyrolysis [6-8]. High content of alkali and silicon contributes to slagging and fouling in boilers and heat transfer surfaces of biomass gasifiers thus decreasing the overall thermal efficiency $[9,10]$.

For biochemical conversion, increased mineral directly correlates to a reduction in carbohydrate content of the feedstock reducing sugars' yield. Weiss et al. [11] determined that pretreatment performance was negatively correlated to neutralization capacity and ash content, reducing both monomeric xylose and total xylose yield from pretreatment. Results also suggest that acid-neutralizing compounds were in the soil and not in the ash. Importantly, both soil (non-physiological ash) 
and physiological-bound ash, which is bound in the cell walls and incorporated into the vascular structure increased mineral content, will most likely increase water treatment cost and will likely be solubilized in the pretreatment and biological conversion processes resulting in mineral contaminants being observed in the sugars' intermediate products.

In all biomass conversion processes, the direct impact of high ash content, whether from physiological ash or from soil contamination, is the increased cost and logistical implications of solid waste disposal. An increase of $5 \%$ ash in a biomass feedstock for a 2,000-T/day conversion refinery would correlate to $\sim 32,000$ T of solid waste annually (assuming $\sim 320$ days of operation). Humbird et al. [12] estimated waste disposal costs of US $\$ 28.86$ per ton, accounting for 2.5 cents of the $\$ 2.15$ per gallon minimum ethanol selling price, and results in waste disposal costs exceeding \$1 M annually. Entrained ash, i.e., soil, is largely a property of feedstock handling methods and can be mitigated through harvesting operations, best management practices, and mechanical separation [13]. Physiological-bound minerals, termed "structural ash," results from intrinsic biomass properties such as plant type, maturity, and anatomical fractions and will require advanced preprocessing methods to effectively remove the bound minerals. Structural ash can vary widely, both in quantity and in composition, in different types of biomass. Pine pulp generally has a very low ash content $(0.5 \%)$, while miscanthus and corn stover have ash content of about $8-10 \%$, and rice hulls have ash content as high as $21 \%[9,10]$. An effective process of the demineralization of biomass ash without degrading hemicellulose, cellulose, and lignin is necessary for improving the conversion processes and reducing waste disposal costs.

Previous research has reported various methods for the demineralization of woody and grassy biomass. Mourant et al. [14] reported that an extraction using hot, deionized water was effective for removing the monovalent cations $\mathrm{Na}$ and $\mathrm{K}$ and divalent cation $\mathrm{Mg}$. Another effective procedure was reported by Scott et al. [15] using a strong acid (0.1 wt $\%$ $\mathrm{HNO}_{3}$ ) hydrolysis for $60 \mathrm{~min}$ at $30^{\circ} \mathrm{C}$. The reaction removed most of the alkaline ions, but hemicellulose was also removed, and the degree of polymerization (DP) of cellulose was significantly reduced. Dobele et al. [16] reported that a $2 \mathrm{wt} \%$ $\mathrm{H}_{3} \mathrm{PO}_{4}$ hydrolysis procedure was effective for demineralization, but most of the levoglucosan produced in subsequent pyrolysis was converted to levoglucosone, a less desirable intermediate product.

Chelating agents are commonly used for removing metal (inorganic) ions in soil research and other industries [17]. A chelating agent, or chelant, contains two or more electron donor atoms that can form coordinate bonds to a single metal atom. After such initial coordinate bond, each successive donor atom that binds creates a ring containing the metal atom. This cyclic structure is called a chelation complex or chelate, the name deriving from the Greek word chele meaning "the great claw of the lobster" [17]. Chelation is a system based on chemical equilibrium and may be used to control metal ion concentrations. A chelation complex usually has solubility properties that are markedly different from both the free metal ion and chelating agent. Chelation has many common industrial applications, including metal buffering, corrosion inhibition, solubilization, and cancer therapy [18].

The citrate ion is a common organic chelating agent which is biodegradable, environmentally friendly, and cost effective compared to other chelates or even other organic acids. The chelation characteristics of citric acid and its derivatives are such that it is widely used in various applications, from soil amendment to consumer products [18]. The chelation of essential metal nutrients with citric acid is very popular in the food and fertilizer industries. The citrate ion can form bi-, tri-, and multi-dentate complexes, depending upon the type of metal ion [19]. For example, metals like iron and nickel form bi-dentate, mononuclear complexes with two of the carboxylic acid groups of the citric acid molecule. Copper, cadmium, and lead form tri-dentate, mononuclear complexes with citric acid utilizing two carboxylic acid groups and a hydroxyl group [20]. Tetra-dentate compounds with silicate anion can be formed with two citric acid molecules utilizing two carboxylic acid groups of each citric acid ion.

The main goal of this work was to examine the demineralization capabilities of several organic chelating agents on corn stover. Because hemicelluloses and cellulose are reactive in acidic environments, acids have the potential to hydrolyze biomass and degrade hemicellulose and cellulose. Using the conjugate base alleviates this problem of hydrolysis and still utilizes the chelating properties of the organic anion. Demineralization of corn stover using four organic acids (formic, oxalic, citric, and tartaric) and sodium citrate was examined. The demineralized products were analyzed for the degradation of hemicellulose, cellulose, and lignin.

\section{Experimental}

\subsection{Materials}

The INL procured three bales of corn stover from Emmetsburg, Iowa, and initially ground them using a Bliss Hammermill (Ponca City, OK) to $6.4 \mathrm{~mm}$. The material was then sequentially ground to $2 \mathrm{~mm}$ using the Thomas Wiley Model 4 Mill (Ramsey, MN), and the samples were stored in 5 -gal buckets until analysis and/or treatment. Four buckets of ground corn stover were provided to the University of Nevada, Reno, where the samples were mixed manually prior to hydrothermal preprocessing. Particles have the arithmetic mean diameter of $0.72 \pm 0.20 \mathrm{~mm}$. 


\subsection{Organic chelation treatments}

Chelation reactions of raw corn stover were performed in a 2-1 Parr reactor, and data reported here are the average and standard deviation for at least three repetitions. Chelating agents bind metal ions in covalent bonds and thus can remove the metal ions from the cross-linked structure of the biomass. Several organic chelating agents, including citric acid, sodium citrate, tartaric acid, oxalic acid, and formic acid, were evaluated for the efficiency of structural inorganic removal from corn stover.

Figure 1 shows the experimental procedure of chelation using chelating agents. For the effective removal of structurally bound inorganics (i.e., structural ash) by chelating agents, the loose dirt and other non-structural, polar inorganics were removed first by washing the sample with boiling water. Acetone was then used for the removal of non-polar extractives. This treatment prepares a dirt-free extractive-free biomass, which allows for more consistency when studying the effects of chelation on structural ash. The solid residue was subjected to chelation and mild hydrothermal treatment in a 21 Parr reactor with various concentrations of chelating agent for $2 \mathrm{~h}$ at $130^{\circ} \mathrm{C}$. The degradation temperature of citric acid is $170^{\circ} \mathrm{C}$, which can be reduced in a pressurized system [21], so the temperature of $130{ }^{\circ} \mathrm{C}$ was chosen to avoid the possible degradation of the chelant. Reactor pressure was monitored and was consistently at, or near, the vapor pressure of water

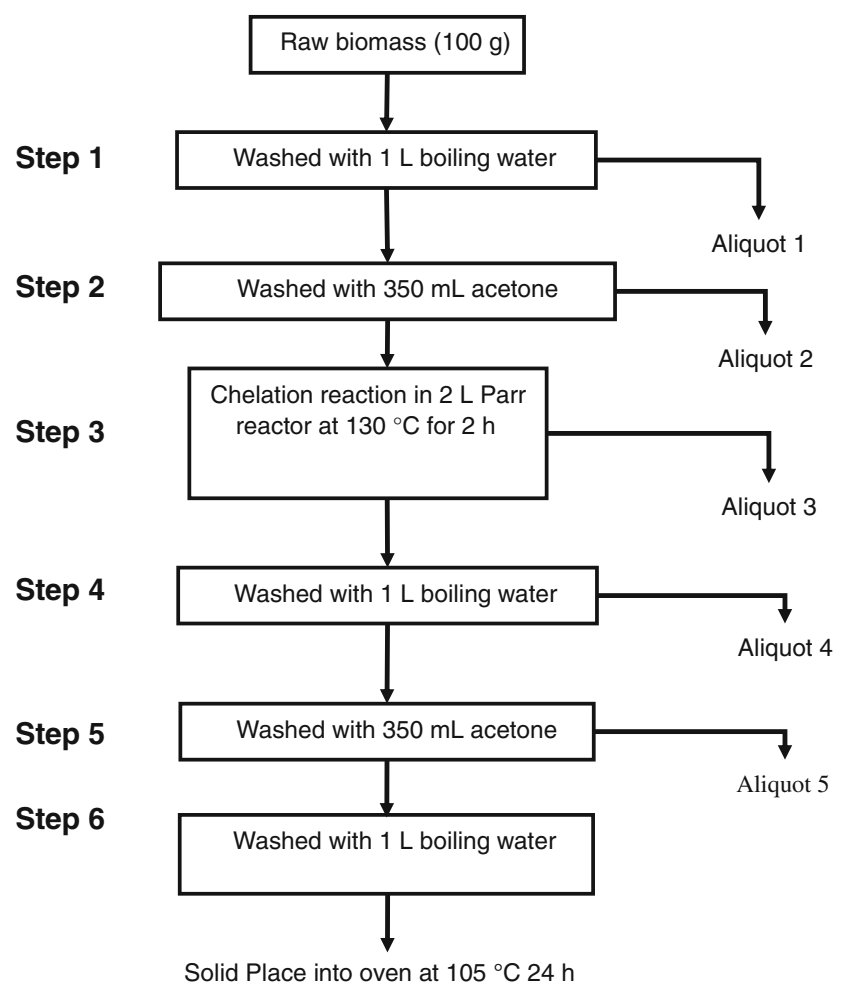

Fig. 1 Block diagram illustrating the experimental procedure for the hydrothermal treatment of corn stover with chelation
(2.7 bar). After chelation, the Parr reactor was cooled by submersion in an ice-water bath. Wet filtration through a 100 Tyler mesh was used to filter the solid residue from a liquid filtrate. Boiling water was applied for $5 \mathrm{~min}$ to remove the chelated metals on the surface of the solid residue. Acetone was used afterward to precipitate unreacted citrate ions into aldoles for removal. Aliquots from each of the washing steps was taken and refrigerated for further analyses. Finally, the solid fraction was collected and placed into a $105{ }^{\circ} \mathrm{C}$ oven to dry and then stored in a ziplock bag until further use.

\subsection{Compositional analysis}

Chemical analysis of the untreated corn stover and the chelation-treated samples was conducted using the following standard methods from the NREL biomass program [22]: Determination of Ash in Biomass; Determination of Extractives in Biomass; Determination of Protein Content in Biomass; Determination of Acid Soluble Lignin Concentration Curve by UV-Vis Spectroscopy; Determination of Structural Carbohydrates and Lignin in Biomass; Standard Test Method for Moisture, Total Solids, and Total Dissolved Solids in Biomass Slurry and Liquid Process Samples; Preparation of Samples for Compositional Analysis.

\subsection{Proximate analysis}

The Na citrate-treated and untreated corn stovers were analyzed with a LECO TGA701 Thermogravimetric Analyzer (St. Joseph, MI) for moisture, volatiles, ash, and fixed carbon content. The instrument was heated to $107^{\circ} \mathrm{C}$ and held there until a constant mass was reached under 10 liters per minute (lpm) UHP nitrogen flow to measure the moisture content. The crucibles were capped with ceramic covers, and the temperature was then ramped to $950{ }^{\circ} \mathrm{C}$ and held there for $7 \mathrm{~min}$ to determine volatiles. The instrument was cooled to $600^{\circ} \mathrm{C}$, the covers were removed, and the gas was switched to a flow of $3.5 \mathrm{lpm}$ of oxygen. The temperature was then increased to $750{ }^{\circ} \mathrm{C}$ and was held until a constant mass was reached for an ash measurement. Fixed carbon was determined by the weight loss between the volatile measurement and the ash measurement.

\subsection{Ultimate analysis}

The determination of $\mathrm{CHN}$ and $\mathrm{S}$ for both the treated and untreated corn stover was performed using a LECO TruSpec CHN and S add-on module (St. Joseph, MI), while oxygen was determined by difference. The moisture from the proximate analysis (performed simultaneously) was used to correct for a "dry-basis" analysis. 
2.6 Attenuated total reflectance-Fourier transform infrared spectroscopy (ATR-FTIR)

A Perkin-Elmer Spectrum 2,000 ATR-FTIR with mid- and far-IR capabilities was used on the raw and pretreated biomass. IR spectra of raw corn stover as well as sodium citratetreated corn stover were recorded at $30^{\circ} \mathrm{C}$ using ATR-FTIR. All samples were milled into fine powder for homogeneity and dried at $105^{\circ} \mathrm{C}$ for $24 \mathrm{~h}$ in an oven prior to FTIR. Only 5$10 \mathrm{mg}$ of dry sample was placed in the FTIR for this analysis and pressed against the instrument's diamond surface with its metal rod. All spectra were obtained using 200 scans for the background (air) and 32 scans for the samples, which were scanned from $500-4,000 \mathrm{~cm}^{-1}$. To study the organic bands of sodium citrate-treated samples from IR spectra, only fingerprint region $\left(800-1,800 \mathrm{~cm}^{-1}\right)$ is presented here.

\subsection{Inductively coupled plasma (ICP) analyses}

A Varian Vista Pro ICP-AES (Cary, NC) was used for inorganic analysis. Acid digestion was used to dissolve solid samples for inductively coupled plasma atomic emission spectroscopy (ICP-AES). A volume of $5 \mathrm{ml}$ of $99.5 \% \mathrm{HNO}_{3}$ was added to $0.4 \mathrm{~g}$ of dry solid sample. A volume of $0.5 \mathrm{ml}$ of $50 \%$ $(v / v)$ hydrofluoric acid (HF) was added to the solution to dissolve $\mathrm{SiO}_{2}$. Liquid argon, at the rate of $88 \mathrm{ml} / \mathrm{min}$, was used as carrier. The liquid solution was heated to $80^{\circ} \mathrm{C}$ and maintained at that temperature for $4 \mathrm{~h}$. After $4 \mathrm{~h}$, the sample was removed from the oven and cooled for $5 \mathrm{~h}$. To prevent HF from reacting with the torch, a 0.5 -g solid $98 \%$ boric acid was put into the solution so that the unreacted HF would react with $\mathrm{B}(\mathrm{OH})_{3}$ to form fluoroboric acid $\left(\mathrm{HBF}_{4}\right)$, which is invisible and not harmful for the ICP-AES torch at room temperature [23]. The solution was diluted 20-200 times before injection into the ICP-AES instrument with a $5 \%$ ethanol/water solution used as the solvent.

A Thermo Scientific iCAP 6,000 Series ICP optical emission spectrometer (ICP-OES) (Waltham, MA) was used to analyze the elements $\mathrm{K}, \mathrm{Ca}, \mathrm{P}, \mathrm{S}, \mathrm{Mg}, \mathrm{Mn}, \mathrm{Na}$, and $\mathrm{Si}$ in the liquid fractions from the chelation treatment for a select number of samples. The samples that were analyzed were the liquid fractions and their solid precipitates from the five steps in Fig. 2 from the $0.05-\mathrm{g} \mathrm{Na}$ citrate treatment. These samples were treated with the same digestion procedure as the ICPAES analysis listed above. The reproducibility of these ICP measurements is quite good, with a standard deviation generally less than $0.1 \%$, and the error bars of ICP measurements is left off the figures for clarity.

\subsection{Ion chromatography (IC) analysis}

The liquid fractions and washings were also analyzed for their anions using IC analysis. A Dionex ICS-3,000 instrument was used to measure the anions $\mathrm{F}, \mathrm{Cl}$, and $\mathrm{Br}$ with a Dionex ASRS 300 (anion self-regenerator suppressor) and Dionex IonPac AS18 anion-exchange column (Sunnyvale, CA). The sample preparation was the same for the ICP-OES analysis. All standards used in the procedure met the ISO 9001 qualifications.

\subsection{Higher heating value}

The higher heating values (HHV) for the untreated biomass and the Na citrate-treated samples were measured following
Fig. 2 Structural ash of solid corn stover treated with various chelates. Data are reported on a dry, extractive-free basis as a mass fraction

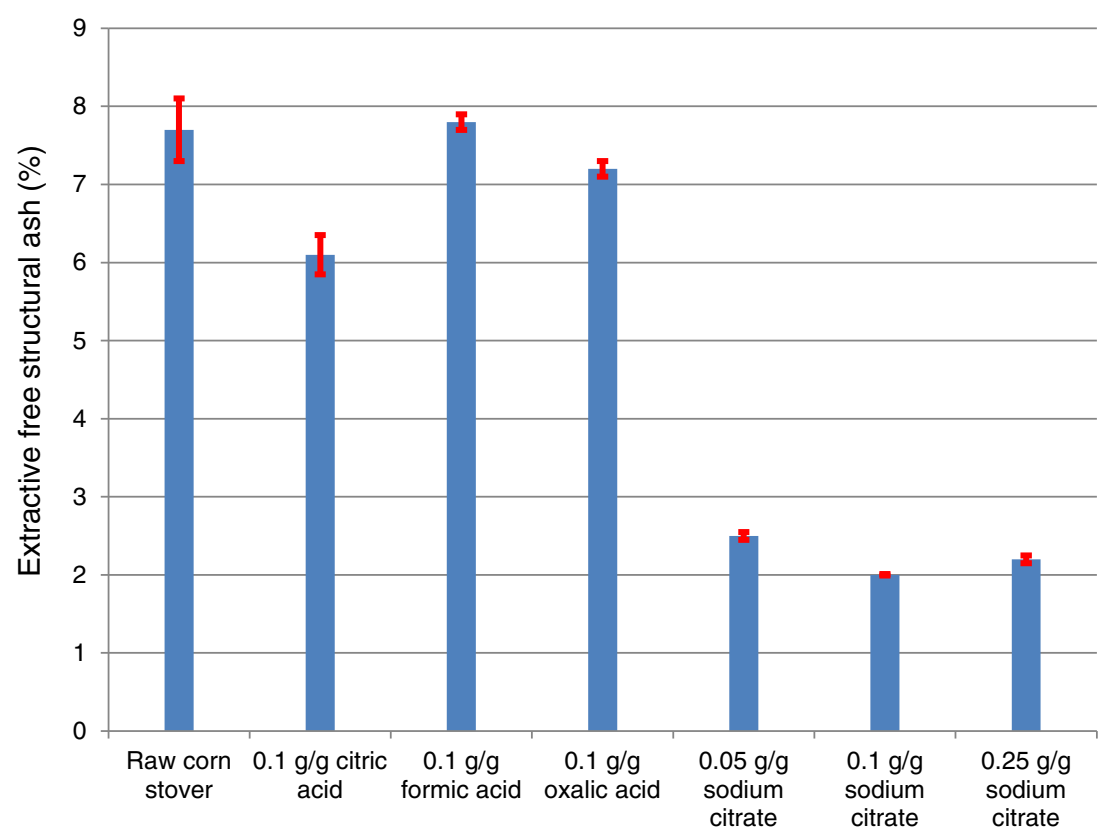


the ASTM D1826 method using a Parr 1,241 adiabatic oxygen bomb calorimeter (Moline, IL) fitted with continuous temperature recording. All samples $(0.5 \mathrm{~g}$ each $)$ were dried at $105{ }^{\circ} \mathrm{C}$ for $24 \mathrm{~h}$ prior to analysis, and $\mathrm{HHV}$ are reported on a dry basis (ash included), distinct from the more common reporting of dry ash-free basis.

\section{Results and discussion}

\subsection{Treatment of corn stover with various organic chelates}

As a preliminary screening tool, total ash analysis of solid samples was used to identify promising chelants. The content of raw corn stover was $10.5 \%$ whole ash (including the loose soil from harvesting), $7.0 \%$ structural ash, and $9.2 \%$ extractives (including starches, proteins, simple sugars, organic acids, etc.) The following chelation experiments were conducted at conditions at which those extractives would be removed from the biomass. A baseline was established for structural ash on an "extractive-free" basis, which is $7.7 \%$. Any treatment that resulted in a solid with structural ash less than $7.7 \%$ on this basis was identified as one that reduced ash content. In all cases, fractions of biomass are reported as a mass fraction. The ash content of various treated solid residues is presented in Fig. 2. With the exception of that treated in formic acid, each dry solid residue had less than $7.7 \%$ ash content, meaning each of them was effective at removing structural ash. Formic acid proved to be the least effective for removing structural ash, as it has only one carboxyl "hand," and so its capacity for binding to metals is limited. Oxalic acid has two carboxylic groups and reduced the structural ash content more than formic acid but was still not the most effective treatment. Citric acid and sodium citrate each have three carboxylic groups along with one hydroxyl group and are excellent chelating agents. Corn stover treated with $10 \%$ citric acid (mass of acid per mass of dry biomass) had a $6.0 \%$ ash content, meaning that $23 \%$ of the structural ash was removed.

Sodium citrate showed the highest reduction of structural inorganics among the chelating agents considered. Treatment with as little as $5 \%$ sodium citrate, with respect to dry corn stover, reduced the structural ash by $66 \%$, and treatment with 10 and $25 \%$ sodium citrate resulted in a further removal of structural ash. One possible explanation of sodium citrate superiority relative to citric acid might be the higher $\mathrm{pH}$ of the solution. A $10 \%$ citric acid solution has a $\mathrm{pH}$ of 3.8 while a $4 \%$ sodium citrate solution has the $\mathrm{pH} 7.5$. At lower temperatures, hemicellulose and cellulose are reactive in acidic media while lignin remains inert [24]. But in a slightly basic solution, lignin is reactive, and cellulose and hemicelluloses are inert [25]. Because structural inorganics form covalent bonds within the cross-linked structure of lignin, the solution should be slightly basic to dissolve lignin-bound metals [8]. Cellulose has a unique structure, and there is little or no possibility of forming bonds between the inorganic molecules and cellulose. Hemicellulose has the potential to bind some inorganics, but research has shown that a hydrothermal carbonization treatment at $200{ }^{\circ} \mathrm{C}$ degrades all hemicelluloses while the ash content is not reduced significantly $[9,24]$. The sodium citrate makes it possible for the lignin to depolymerize and for the citrate ion to form bonds with the metal ions. As a result, the inorganic metal is removed as a chelate. Note that the cation $\mathrm{Na}$ is left behind on the biomass and cannot be completely removed by water and acetone washings alone. Therefore, the potential exists to use a different chelating agent, such as ammonium citrate, to further reduce ash content.

\subsection{Chemical analysis of sodium citrate treated solid residue}

The previous section describes the promising results of inorganic removal from corn stover using sodium citrate as a chelating agent. Adding 10 and $25 \mathrm{~g}$ of sodium citrate to $100 \mathrm{~g}$ of dry raw corn stover yields similar ash contents, about $80 \%$ reduction from the raw corn stover. This may indicate that an optimal concentration of $\mathrm{Na}$ citrate is between 5 and $10 \mathrm{~g}$ for the $100 \mathrm{~g}$ of corn stover under the experimental conditions of $130^{\circ} \mathrm{C}, 2 \mathrm{~h}$, and a $10: 1$ water to biomass ratio. In this section the chemical characteristics of sodium-citrate treated corn stover will be discussed compared with raw corn stover. Corn stover treated by two different concentrations of sodium citrate, 0.05 and $0.10 \mathrm{~g} / \mathrm{g}$, were selected for analysis.

Table 1 shows the chemical analyses of sodium citratetreated solid residues. Because of the washing steps before and after the chelation process (Fig. 1), extractable inorganics, protein content, and total extractives are significantly reduced.

Table 1 Chemical analysis of sodium citrate-treated corn stover solid residues

\begin{tabular}{lccc}
\hline Sample description & $\begin{array}{l}\text { Raw corn } \\
\text { stover (\%) }\end{array}$ & $\begin{array}{l}0.05 \mathrm{~g} / \mathrm{g} \mathrm{Na} \\
\text { citrate }(\%)\end{array}$ & $\begin{array}{l}0.10 \mathrm{~g} / \mathrm{g} \mathrm{Na} \\
\text { citrate }(\%)\end{array}$ \\
\hline Structural ash & $7.7 \pm 0.8$ & $2.5 \pm 0.1$ & $2.0 \pm 0.0$ \\
Extractable inorganics & $2.0 \pm 0.5$ & $0.4 \pm 0.3$ & $0.4 \pm 0.3$ \\
Whole protein & $2.5 \pm 0.0$ & $1.0 \pm 0.0$ & $1.0 \pm 0.0$ \\
Structural protein & $1.7 \pm 0.0$ & $1.1 \pm 0.0$ & $0.9 \pm 0.0$ \\
Extractable protein & $0.9 \pm 0.0$ & $0.0 \pm 0.0$ & $0.2 \pm 0.0$ \\
Lignin & $18.5 \pm 0.2$ & $16.5 \pm 0.6$ & $15.7 \pm 0.1$ \\
Glucan & $39.2 \pm 0.1$ & $39.2 \pm 0.6$ & $39.6 \pm 0.4$ \\
Xylan & $25.6 \pm 0.7$ & $26.7 \pm 0.1$ & $26.1 \pm 0.5$ \\
Galactan & $2.2 \pm 0.0$ & $1.8 \pm 0.0$ & $1.7 \pm 0.0$ \\
Arabinan & $4.0 \pm 0.0$ & $3.9 \pm 0.0$ & $3.7 \pm 0.1$ \\
Acetic acid & $3.2 \pm 0.1$ & $1.5 \pm 0.0$ & $2.0 \pm 0.0$ \\
\hline
\end{tabular}

Data are reported as a mass fraction on an extractive-free basis 
Concentrations of extractive-free glucan (cellulose) and xylan, galactan, and arabinan (hemicellulose) remain similar after treatment compared to raw biomass. This indicates that cellulose and hemicellulose were not degraded during the sodium citrate treatment. Lignin content was slightly reduced by treatment with sodium citrate.

\subsection{Proximate and ultimate analysis}

The results of proximate and ultimate analysis of raw corn stover and sodium citrate-treated corn stover solid residues are shown in Table 2. Raw corn stover has $78.1 \%$ volatiles, $11.2 \%$ fixed carbon, and $10.5 \%$ ash. The proximate analysis of solid residues treated by 5 and by $10 \%$ sodium citrate is similar. The content of volatiles in samples treated with sodium citrate increases, and ash decreases when compared to raw corn stover. As mineral content is removed, the remaining organic fractions makeup a larger fraction of the treated solid. Ash content is lower in treated samples than raw, but fixed carbon did not increase accordingly. This may indicate some loss of fixed carbon during the treatment. It is possible that lignin partially depolymerizes during the treatment, and the product is volatilized more readily than untreated lignin.

The ultimate analysis of sodium citrate treatment solid residue shows similar hydrogen and nitrogen content compared to the raw corn stover. But an increase of oxygen and carbon percentage can be observed in the treated solid residue compared to raw corn stover. However, calculation of $\mathrm{C}-$ and $\mathrm{O}$ - content on an ash-free basis, as a fraction only of the organic content, shows that oxygen is essentially constant (44\%) while carbon may decrease slightly, from 50 to about $48 \%$ (treatment with $5 \%$ sodium citrate) and $47 \%$ (10\% sodium citrate). The decrease in carbon content is small and may reflect experimental error only. The HHV increases in the treated corn stover compared to that in the untreated samples

Table 2 Proximate and ultimate analysis of untreated corn stover and sodium citrate-treated corn stover

\begin{tabular}{|c|c|c|c|}
\hline Sample Description & $\begin{array}{l}\text { Raw corn } \\
\text { stover }\end{array}$ & $\begin{array}{l}0.05 \mathrm{~g} / \mathrm{g} \\
\text { Na citrate }\end{array}$ & $\begin{array}{l}0.1 \mathrm{~g} / \mathrm{g} \\
\text { Na citrate }\end{array}$ \\
\hline Volatiles (\%) & $78.1 \pm 0.8$ & $86.7 \pm 0.2$ & $85.2 \pm 0.3$ \\
\hline Fixed carbon (\%) & $11.2 \pm 0.6$ & $10.6 \pm 0.2$ & $11.4 \pm 0.3$ \\
\hline Ash (\%) & $10.5 \pm 0.3$ & $2.5 \pm 0.0$ & $2.0 \pm 0.0$ \\
\hline $\mathrm{H}(\%)$ & $5.4 \pm 0.1$ & $5.8 \pm 0.1$ & $5.7 \pm 0.1$ \\
\hline $\mathrm{C}(\%)$ & $44.5 \pm 0.7$ & $47.0 \pm 0.4$ & $46.4 \pm 0.2$ \\
\hline N (\%) & $0.8 \pm 0.0$ & $0.6 \pm 0.0$ & $0.7 \pm 0.0$ \\
\hline $\mathrm{O}(\%)$ & $39.5 \pm 0.7$ & $43.7 \pm 0.4$ & $44.0 \pm 0.3$ \\
\hline HHV (MJ/kg) & $13.6 \pm 0.1$ & $20.5 \pm 0.1$ & $21.2 \pm 0.1$ \\
\hline
\end{tabular}

Data are reported as a mass fraction on an extractive-free basis of the biomass sample. Note: ash reported here is on a total mass basis (not the extractive-free basis) but are similar between the two treatments. Even on an ashfree basis, the HHV content of the solid residue is increased. Near-complete removal of extractive compounds with relatively low HHV might explain this increase in fuel value.

\subsection{FTIR analysis of sodium citrate-treated corn stover}

FTIR spectroscopy has been extensively used in biomass research, as it shows the bond energies of characteristic groups in biomass, and can indicate changes in molecular formulation resulting from various treatments [26]. By identifying the peaks of FTIR spectra, which are caused by the vibrations of functional groups, FTIR allows us to identify and analyze the chemical structure of a sample. Table 3 identifies functional groups for particular wavelengths and the corresponding chemical compounds. Aromatic compounds have weak bonds, and therefore they stretch (vibrate) at lower wave numbers usually from $500-2,000 \mathrm{~cm}^{-1}$. Aliphatic compounds stretch in the higher wave numbers (usually 2,500$4,000 \mathrm{~cm}^{-1}$ ). Biomass is a complex mixture of aromatic compounds, so the fingerprint region $\left(800-1,800 \mathrm{~cm}^{-1}\right)$ is the range of interest here. Figure 3 shows the FTIR spectra of raw and treated corn stover.

Raw corn stover shows strong bonds at $896,1,036,1,186$, $1,244,1,367,1,426$, and 1,618 and $1,733 \mathrm{~cm}^{-1}$ in the fingerprint region. These correspond to the aromatic carbon-hydrogen bond of hemicellulose $(\mathrm{C}-\mathrm{H})$, alcohol group of glucose $(\mathrm{C}-\mathrm{OH})$, pyranose ring of lignin $(\mathrm{C}-\mathrm{O}-\mathrm{C})$, aryl-alkyl ether of lignin $(\mathrm{C}-\mathrm{O}-\mathrm{C})$, aromatic acid of hemicelluloses $(\mathrm{C}-\mathrm{OH})$, methoxy bond of lignin $\left(\mathrm{O}-\mathrm{CH}_{3}\right)$, aromatic carbon skeleton $(\mathrm{C}=\mathrm{C})$, and carbonyl group from hemicellulose $(-\mathrm{C}=\mathrm{O})$, respectively. All of these peaks are sharper after treatment with sodium citrate. Each of these bonds belongs to

Table 3 IR absorption corresponding to various functional groups. ${ }^{10,} 26$ 30,33

\begin{tabular}{lll}
\hline $\begin{array}{l}\text { Wave number } \\
\left(\mathrm{cm}^{-1}\right)\end{array}$ & Functional groups & Possible compounds \\
\hline 1,733 & $\mathrm{C}=\mathrm{O}$ stretching & Ketone and hemicellulose \\
1,638 & $\mathrm{C}=\mathrm{C}$ & Lignin \\
$1,603-1,618$ & $\mathrm{C}=\mathrm{C}$ stretching & Cellulose, lignin \\
1,485 & $\mathrm{O}-\mathrm{CH}_{3}$ & Lignin \\
1,426 & $\mathrm{OH}$ bending & Acid \\
1,367 & $\mathrm{CH}$ bending & Acid \\
1,244 & $\mathrm{C}-\mathrm{O}-\mathrm{C}$ stretching & Cellulose \\
1,213 & $\mathrm{C}-\mathrm{O}$ stretching & Lignin \\
$1,186,1,163$ & $\mathrm{C}-\mathrm{O}-\mathrm{C}$ stretching vibration & Cellulose, lignin \\
$1,140,1,103$ & $\mathrm{OH}$ association & Alcohol, hemicellulose \\
1,036 & $\mathrm{C}-\mathrm{O}$ stretching and & Alcohol \\
896 & $\mathrm{C}-\mathrm{O}$ deformation & Cellulose, hemicellulose \\
\hline
\end{tabular}


Fig. 3 FTIR of raw corn stover and $\mathrm{Na}$ citrate-treated corn stover (fingerprint region); blue raw corn stover, red $0.05 \mathrm{~g} / \mathrm{g} \mathrm{Na}$ citrate, green $0.1 \mathrm{~g} / \mathrm{g}$ Na citrate, cyan blue $0.25 \mathrm{~g} / \mathrm{g}$ Na citrate)

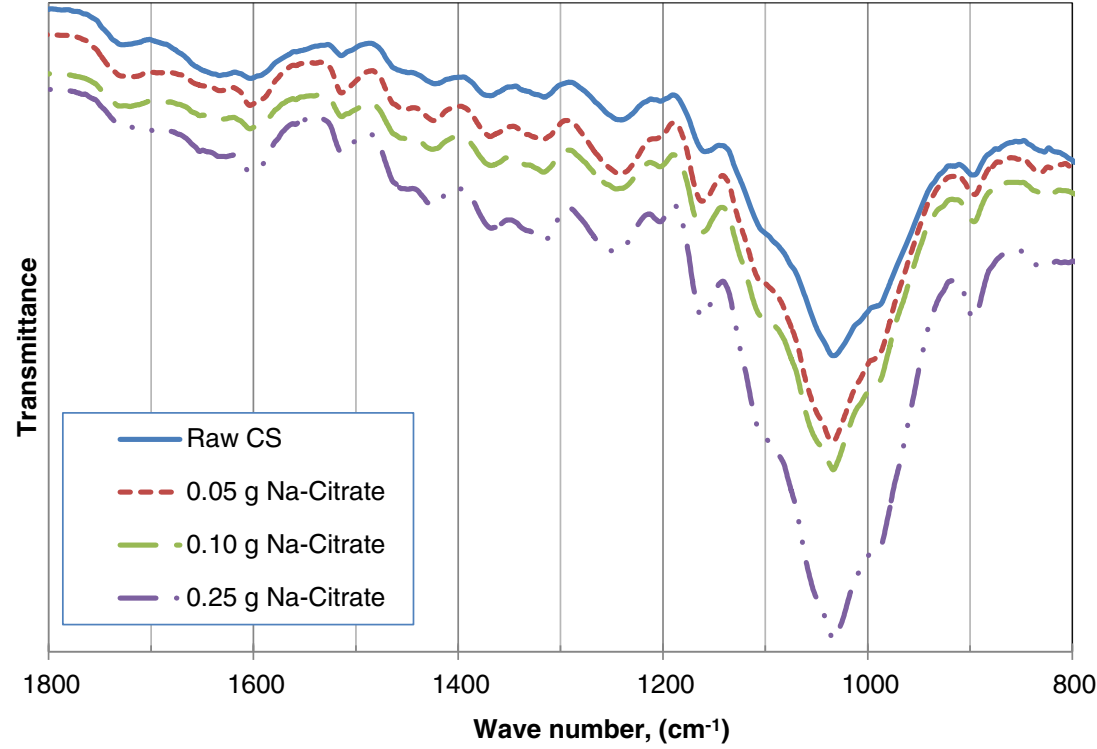

hemicellulose, cellulose, or lignin [27-32]; sharper peaks imply an increased concentration of these components in the sodium citrate-treated samples. The other medium and weak peaks observed at $985,1,103,1,213,1,485$, and 1,638 $\mathrm{cm}^{-1}$ correspond to the aromatic $\mathrm{C}-\mathrm{H}$ bonds of extractives, $\mathrm{OH}$ association, phenolic $(\mathrm{C}-\mathrm{O})$ and methoxy $\left(\mathrm{O}-\mathrm{CH}_{3}\right)$ of lignin, and $\mathrm{C}=\mathrm{C}$ benzene ring stretch, respectively [32]. The bond at $985 \mathrm{~cm}^{-1}$ is shifted to $975 \mathrm{~cm}^{-1}$ for the treated samples, which might result from the degradation of the extractives. Every bond present in raw corn stover is either stronger or unaffected by the treatment, except those bonds corresponding to extractive compounds. The FTIR spectra demonstrate that mild hydrothermal treatment with sodium citrate does not change the chemical structure of hemicelluloses, cellulose, or lignin.

\subsection{Inorganic analysis of sodium citrate-treated solid residue}

The inorganic content of raw corn stover is presented in Table 4. Silicate anion, a tetra-valent element, is the dominant

Table 4 Inorganic concentrations measured by ICP-AES and IC analyses in raw corn stover

Values are reported on a mass basis of dry whole biomass inorganic element of the raw corn stover. Potassium, calcium, aluminum, and sodium are the other main inorganics. ICP and IC analyses were performed on the solid residues treated by three different concentrations of sodium citrate and compared with inorganic analysis of raw corn stover (Fig. 4). Because sodium citrate is a poly-dentate ligand and can be used to remove tetra-valent ions, it can potentially remove silicate anion from biomass. The experimental results seem to confirm this hypothesis.

With the increasing $\mathrm{Na}$ citrate strength, the inorganic elements' concentrations decrease; and as a result, the overall ash decreases. Each $\mathrm{Mg}, \mathrm{S}, \mathrm{P}, \mathrm{Fe}, \mathrm{Cl}$, and $\mathrm{K}$ all seem to decrease rapidly with a little addition of $\mathrm{Na}$ citrate. Potassium and $\mathrm{Cl}$ were removed almost completely with a $0.05-\mathrm{g} / \mathrm{g}$ Na citrate addition. A possible explanation might be the forms of $\mathrm{K}$ and $\mathrm{Cl}$ present in corn stover. Potassium, a monovalent cation, is typically found in the form of a halogen salt [33]. Similarly, $\mathrm{Cl}$, a monovalent anion measured with IC, is also frequently found as an ionic-bound salt such as $\mathrm{NaCl}$ or $\mathrm{KCl}$. These salts are readily dissolved in hot water and can be removed almost completely $(90 \%)$ with no further treatment $[10,33]$. Because the first step of the treatment process is a hot-water wash, which likely removes the majority of $\mathrm{K}$ and $\mathrm{Cl}$, the sodium citrate's strength is likely not a factor for the removal of these monovalent ions. Conversely, the extent of removal of divalent ions $\mathrm{Ca}, \mathrm{Mg}$, and $\mathrm{Fe}$ is correlated with sodium citrate concentration. A $0.05-\mathrm{g} / \mathrm{g}$ sodium citrate reaction removes $80 \%$ of these ions while a $0.25 \mathrm{~g} / \mathrm{g}$ sodium citrate removes more than $93 \%$ of $\mathrm{Ca}, \mathrm{Mg}$, and $\mathrm{Fe}$. Sulfur and $\mathrm{Al}$ content are also effectively reduced with the sodium citrate treatments. With only $0.05 \mathrm{~g} / \mathrm{g}$ of sodium citrate, more than 85 and $89 \%$ of S and Al, respectively, were removed. More than $95 \%$ of both $\mathrm{S}$ and $\mathrm{Al}$ were removed when the sodium citrate concentration was increased to $0.25 \mathrm{~g} / \mathrm{g}$. Silicates, the most abundant 
Fig. 4 Inorganic analysis of sodium citrate-treated corn stover. Data are presented as a percentage of the element remaining in the solid after treatment, relative to the amount in raw corn stover

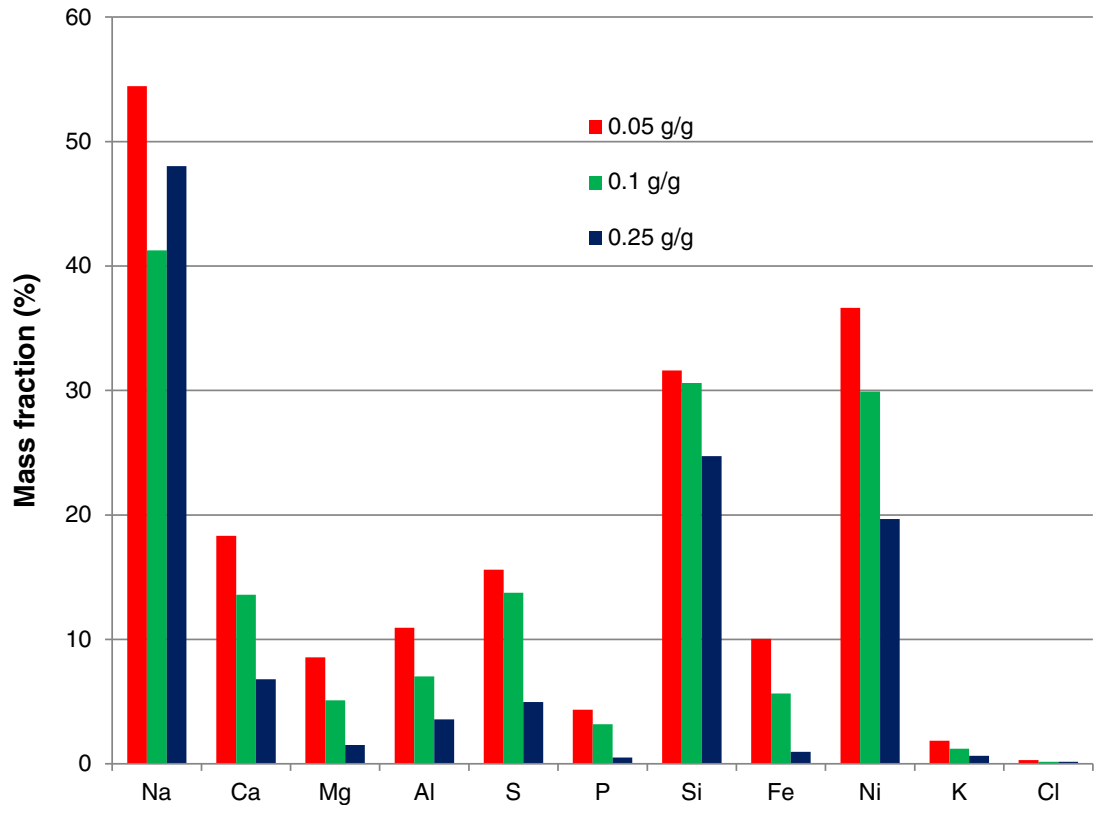

mineral in raw corn stover, is also removed by sodium citrate. Silica can possess multiple valances in biomass, e.g., tetra-, tri-, and/or bi-dentate. With the addition of the citrate ion, poly-dentate $\mathrm{Si}$ and other poly-dentate cations form a soluble chelate and are thus released from the structure of the biomass. With the addition of $0.05 \mathrm{~g} / \mathrm{g}$ of sodium citrate, more than $65 \%$ of Si was removed; and with $0.25 \mathrm{~g} / \mathrm{g}$ of sodium citrate, $75 \%$ of the total Si was removed.

The increase of sodium citrate concentration is effective at removing most metals, but the $\mathrm{Na}$ in sodium citrate itself is apparently deposited on the surface of the treated solid. Sodium deposition by the treatment process masks the reduction in total ash, since the additional $\mathrm{Na}$ deposited accounts for $0.05 \%$ ash increase. Sodium concentration in biomass shown in Fig. 4 also reflects this effect. The sodium concentration apparently decreases when the amount of chelant used in treatment is increased from 0.05 to $0.1 \mathrm{~g} / \mathrm{g}$, but seems to increase when the chelant dosage is further increased to $0.25 \mathrm{~g} / \mathrm{g}$. As discussed above, it is likely that $\mathrm{Na}$ is removed from biomass by the hot-water wash (step 1 of the treatment process, Fig. 1). Thus, it is likely that the sodium shown in Fig. 4 is a by-product of the treatment with sodium citrate. It is possible that a more rigorous rinsing step after chelation would be effective to further reduce the sodium content.

\subsection{Inorganics' mass balance in sodium citrate treatment}

There are five main steps in each demineralization experiment (Fig. 1). Liquid aliquots from every step were collected, digested, and analyzed by ICP. Inorganics found from steps 1 and 2 were assumed to be the non-structural inorganics prior to sodium citrate treatment. As the main goal of this research is to evaluate the removal of structural ash by sodium citrate chelation, the results from steps 3 to 5 are of most interest. It is possible to calculate the amount of each element removed from the biomass for each of the five steps separately. For this inorganic mass balance, the mass of inorganics found in the liquid aliquots by ICP-OES were subtracted from the mass present in the raw solid and are presented in Fig. 5. The elemental metal composition in the biomass remaining after each step of the treatment is seen to decrease with each subsequent step of treatment. Inorganics remaining after step 2 are assumed to be structural inorganics. The inorganic composition remaining in the corn stover after treatment is shown in the last two bars; one calculated by subtracting the sum of all five steps (five liquid samples) from that elemental content in the raw biomass, and the last column shows the elemental composition of treated biomass measured by ICP.

The accuracy of this mass balance is determined by comparing the last two columns of Fig. 5 for each element. The amount of most of the inorganics present in the treated biomass (last column), a direct measurement, is similar to the amount calculated by subtracting the amount found in all the liquid aliquots from the amount present in the untreated biomass (penultimate column). Solids in the aliquots tend to settle, and some dissolved species precipitate slowly over time, which may cause the detected concentrations to be too low, so that the amount predicted in the treated biomass would be higher than that actually found by direct digestion and ICP analysis. This was in fact observed for 10 of the 11 measured elements, $\mathrm{Al}$ being the sole exception.

A major portion of monovalent ions sodium, potassium, and chlorine were leached by steps 1 and 2 (hot-water and acetone washings), as shown in Fig. 5 . About $47 \%$ of the 
Fig. 5 Analysis of inorganic content in corn stover after different steps of the treatment process. Step numbers refer to Fig. 1; structural inorganics is that remaining after step 2 . Treatment is with $0.05 \mathrm{~g}$ of sodium citrate per gram corn stover. Values are reported on a mass basis as a percentage of the treated corn stover

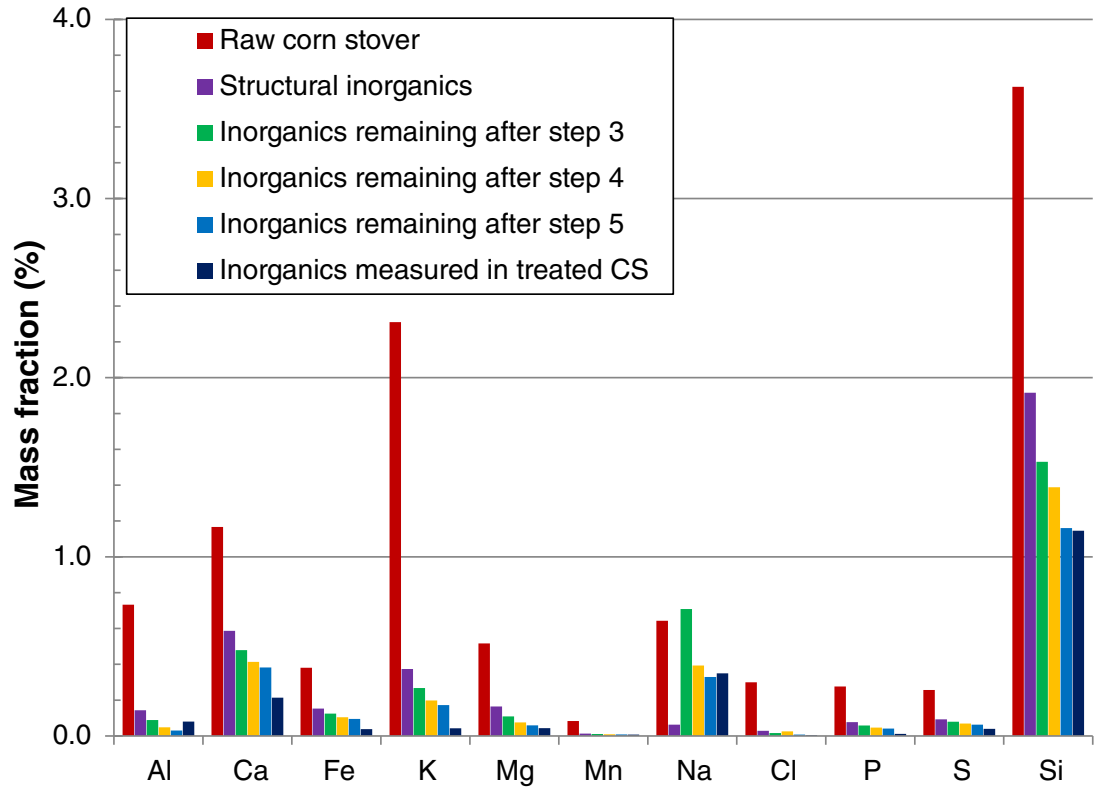

silicate anion was removed by hot-water and acetone wash, which indicates the presence of loose dirt in the raw biomass. After step 2, the calculated remaining inorganic in the treated solid is $6.55 \%$, which is similar to the measured structural ash $(7.0 \%)$.

Additional metals are removed during steps 3, 4, and 5, and the chelation reaction is followed by hot-water and acetone washings. Due to the chelation reaction, the inorganics are extracted from the biomass and bonded with a ligand to form a metal chelate complex. Metal chelates are very soluble and thus require washing to remove them from the external and internal surfaces of the pretreated solid. Steps 4 and 5 help to remove the metal chelates from the solid surfaces; those steps by themselves are not capable of dissolving inorganics, without the prior chelation of step 3 .

Silicon is significantly leached due to the chelation reaction. Citrate ions have a higher affinity for higher valence $(+4$, $+3)$ cations than for lower ones $(+2,+1)$ [18]. Silicon ion is a poly-valent cation $(+4,+2)$, and thus citrate is effective for bonding with and dissolving Si. Based on the stoichiometry of the citrate ion, which has three active binding sites, two citrate ions are required to make a chelation complex with one $\mathrm{Si}^{+4}$ ion. But the other two empty available sites of those two citrate ions are available and can bind another divalent ion. If only $\mathrm{Si}$ is considered, four citrate ions may be required to bind three $\mathrm{Si}$ ions and make a citrate silica organometallic complex. Based on this assumption, then, $5 \mathrm{~g}$ of sodium citrate can bind as much as $0.36 \mathrm{~g}$ of $\mathrm{Si}$. Because structural $\mathrm{Si}$ was decreased by 0.74 from $100 \mathrm{~g}$ of raw biomass sample treated with $5 \mathrm{~g}$ sodium citrate, citrate might not act strictly as a trivalent binder. Sometimes, citrate can release a hydroxy ion and become a tetra-valent chelating agent [19], in which case it can potentially bind as much as one Si atom per citrate. The exact electronic state of $\mathrm{Si}$ in corn stover is not known, and further research is required. For example, X-ray diffraction or dynamic NMR might shed light on the chelation binding mechanisms.

Similar to Si removal, sodium citrate treatment also decreases the structural (i.e., ash remaining after step 2) Al, Fe, $\mathrm{Ca}, \mathrm{Mg}, \mathrm{S}$, and K. About 32-64\% of those structural elements were removed by sodium citrate chelation in steps 3,4 , and 5 . Sodium decreased significantly with the hot-water and acetone washing (step 2). But with the addition of sodium citrate, sodium concentration in the solid increased. In fact, adding $5 \mathrm{~g}$ of tri-sodium citrate means an introduction of $1.17 \mathrm{~g}$ of $\mathrm{Na}$. Due to the high concentration, only a portion of this additional sodium was able to be removed by rinsing in steps 4 and 5 . This is likely the reason for the sodium concentration increasing from 0.06 to $0.7 \%$ after step 3. As shown in Fig. 5, after step 4 , about $45 \%$ of sodium is removed compared to step 3, and it further leached with step 5 to $54 \%$ compared to step 3 . The use of acetone in step 5 does not reduce significantly inorganic content. It is possible that step 5 could be omitted to achieve the same amount of ash reduction.

Corn stover treated with $0.05 \mathrm{~g}$ of sodium citrate per gram of raw biomass shows structural ash reduced from 7.0 to $2.5 \%$. Based on the stoichiometric balance, $5 \%$ sodium citrate is not adequate to remove all structural ash. This is why further reduction of ash is found for treatment with a higher strength of sodium citrate (Section 3.1). With the addition of sodium citrate, structural ash is reduced, but sodium is deposited simultaneously. With the intended goal of reducing overall ash, it is obviously counterproductive to add one metal (sodium) as part of the process. Use of alternative conjugate citrate bases like ammonium citrate might resolve this issue. Citrate, in this work, was not recovered. Further 
development of this technology will require the identification of a process for citrate recovery, perhaps by ion exchange or with strong acid resin.

\section{Conclusions}

Sodium citrate removes structural ash from corn stover without affecting cellulose, hemicellulose, and lignin. Adding $25 \mathrm{~g}$ of sodium citrate to $100 \mathrm{~g}$ of dry corn stover can reduce $77 \%$ of the structural ash. However, sodium concentration is increased in the solid product by this treatment process. It is likely that the use of other citrates, such as ammonium citrate, can further reduce ash. Further investigation to the reaction chemistry is indicated. If an economic process for chelant recovery and regeneration is identified, then this chelation preprocess might play a significant role in providing a commodity-grade biomass for a commercial biorefinery industry.

Acknowledgments The authors gratefully acknowledge the support by the Department of Energy (Contract Number: DE-AC07-05ID14517, and DE-EE 0000272). The authors acknowledge meaningful conversations with Joan G. Lynam of the University of Nevada. The authors also acknowledge Chris Sladek, research associate, for his support with analytical instrumentation.

Open Access This article is distributed under the terms of the Creative Commons Attribution License which permits any use, distribution, and reproduction in any medium, provided the original author(s) and the source are credited.

\section{References}

1. Kenney KL, Ovard LP, Hess JR (2013) Summary report. U.S. Department of Energy. Biomass Densification Workshop: transforming raw biomass to feedstock. Idaho National Laboratory, Idaho Falls, 2012

2. Perlack RD, Stokes BJ (2011) U.S. Department of Energy. U.S. Billion-Ton Update: Biomass Supply for a Bioenergy and Bioproducts Industry. ORNL/TM-2011/224. Oak Ridge National Laboratory, Oak Ridge

3. Gilbert P, Ryu C, Sharifi V, Swithenbank J (2006) Effect of process parameters on pelletisation of herbaceous crops. Fuel 88:1491-1497

4. Michel R, Rapagna S, Di Marcello M, Burg P, Matt M, Courson C, Gruber R (2011) Catalytic steam gasification of Miscanthus X giganteus in fluidised bed reactor. Fuel Process Inst 92:1169-1177

5. Sokhansanj S, Fenton J (2006) Cost benefit of biomass supply and pre-processing enterprises in Canada. Biocap, Canada

6. Mercader FDM, Groeneveld MJ, Kersten SRA, Way NWJ, Schaverien CJ, Hogendoorn JA (2010) Production of advanced biofuels: co-processing of upgraded pyrolysis oil in standard refinery units. Appl Catal B Environ 96:57-66

7. DeGroot WF, Richards GN (1988) The effects of ion-exchanged cobalt catalysts on the gasification of wood chars in carbon dioxide. Fuel 67:345-351

8. Oudenhoven SRG, Westerhof RJM, Aldenkamp N, Brilman DWF, Kersten SRA (2013) Demineralization of wood using wood-derived acid: towards a selective pyrolysis process for fuel and chemicals production. J Anal Appl Pyrol 103:112-118. doi:10.1016/j.jaap. 2012.10.002

9. Reza MT, Lynam JG, Uddin MH, Coronella CJ (2013) Hydrothermal carbonization: fate of inorganics. Biomass Bioenergy 49:86-94

10. Miles TR, Jenkins BM, Baxter L, Miles TRJ, Bryers RW, Oden LL (1996) Boiler deposits from firing biomass fuels. Biomass Bioenergy 10(2-3): 125-138

11. Weiss ND, Farmer JD, Schell DJ (2010) Impact of corn stover composition on hemicellulose conversion during dilute acid pretreatment and enzymatic cellulose digestibility of the pretreated solids. Bioresour Technol 101(2):674-678

12. Humbird DA, Davis R, Tao L, Kinchin C, Hsu D, Aden A (2011) Process design and economics for biochemical conversion of lignocellulosic biomass to ethanol. Dilute-acid pretreatment and enzymatic hydrolysis of corn stover. National Renewable Energy Laboratory, Golden

13. Kenney KL, Smith WA, Gresham GL, Westover TL (2013) Understanding biomass feedstock variability. Biofuels 4(1):111-127

14. Mourant D, Wang Z, He M, Wang XS, Garcia-Perez M, Ling K, Li CZ (2011) Mallee wood fast pyrolysis: effects of alkali and alkaline earth metallic species on the yield and composition of bio-oil. Fuel 90:2915-2922

15. Scott DS, Paterson L, Piskorz J, Radlein D (2001) Pretreatment of poplar wood for fast pyrolysis: rate of cation removal. J Anal Appl Pyrol 57:169-176

16. Dobele G, Dizhbite T, Rossinskaja G, Telysheva G, Meier D, Radtke S, Faix O (2003) Pre-treatment of biomass with phosphoric acid prior to fast pyrolysis: a promising method for obtaining 1,6anhydrosaccharides in high yields. J Anal Appl Pyrol 68-69:197-211

17. Kirk-Othmer Encyclopedia of Chemical Technology, John Wiley \& Sons Inc. vol 5. Edition 4 doi: 10.1002/0471238961

18. Kirk-Othmer Encyclopedia of chemical technology, John Wiley \& Sons Inc., vol 6. edition 4 doi: 10.1002/0471238961

19. Bassi R, Prasher SO, Simpson BK (2000) Extraction of metals from a contaminated sandy soil using citric acid. Environ Prog Sust Energ 19(4):275-282

20. Francis AJ (1992) Biodegradation of metal-citrate complexes and implications for toxic metal mobility. Nature 356:140-142

21. Berovic M, Legisa M (2007) Citric acid production. Biotechnol Annu Rev 13:303-343

22. Sluiter J, Sluiter A (2010) Summative mass closure-laboratory analytical procedure (lap) review and integration: feedstocks. National Renewable Energy Laboratory, Golden, NREL Report No. TP-510-48087

23. Flood DT (1933) Fluorobenzene. Org Synth 13(2):295-298

24. Lynam JG, Coronella CJ, Yan W, Reza MT, Vasquez VR (2011) Acetic acid and lithium chloride effects on hydrothermal carbonization of lignocellulosic biomass. Bioresour Technol 102:6192-6199

25. Peterson AA, Vogel F, Lachance RP, Froling M, Antal MJ, Tester JW (2008) Thermochemical biofuel production in hydrothermal media: a review of sub- and supercritical water technologies. Energy Environ Sci 1:32-65

26. Reza MT (2013) Upgrading biomass by hydrothermal and chemical conditioning. PhD dissertation, University of Nevada Reno

27. Lee SJ, Kim BK (2012) Covalent incorporation of starch derivative into waterborne polyurethane for biodegradability. Carbohydr Polym 87(2):1803-1809

28. Rosa S, Rehman N, de-Miranda M, Nachtingall S, Bica C (2012) Chlorine-free extraction of cellulose from rice husk and whisker isolation. Carbohydr Polym 87:1131-1138

29. Sun XF, Sun RC, Su Y, Sun JX (2004) Comparative study of crude and purified cellulose from wheat straw. J Agric Food Chem 52:839-847 
30. Viera RGP, Rodrigues G, Assunção RMN, Meireles CS, Vieira J, Oliveira GS (2007) Synthesis and characterization of methylcellulose from sugarcane bagasse cellulose. Carbohydr Polym 67:182-189

31. Reza MT, Uddin MH, Lynam JG, Coronella CJ (2014) Engineered pellets from dry torrefied and HTC biochar blends. Biomass Bioenergy 63:229-238
32. Reza MT, Uddin MH, Lynam JG, Hoekman SK, Coronella CJ (2014) Hydrothermal carbonization of loblolly pine: reaction chemistry and water balance. Biomass Conv Bioref. doi:10.1007/s13399-014-0115-9

33. Saddawi A, Jones JM, Williams A, Le Coeur C (2012) Commodity fuels from biomass through pretreatment and torrefaction: effects of mineral content on torrefied fuel characteristics and quality. Energy Fuel 26:6466-6474 